NASA/TM-2008-215428

\title{
Performance of Subscale Docking Seals Under Simulated Temperature Conditions
}

Ian M. Smith and Christopher C. Daniels

The University of Akron, Akron, Ohio

Patrick H. Dunlap and Bruce M. Steinetz

Glenn Research Center, Cleveland, Ohio 


\section{NASA STI Program . . . in Profile}

Since its founding, NASA has been dedicated to the advancement of aeronautics and space science. The NASA Scientific and Technical Information (STI) program plays a key part in helping NASA maintain this important role.

The NASA STI Program operates under the auspices of the Agency Chief Information Officer. It collects, organizes, provides for archiving, and disseminates NASA's STI. The NASA STI program provides access to the NASA Aeronautics and Space Database and its public interface, the NASA Technical Reports Server, thus providing one of the largest collections of aeronautical and space science STI in the world. Results are published in both non-NASA channels and by NASA in the NASA STI Report Series, which includes the following report types:

- TECHNICAL PUBLICATION. Reports of completed research or a major significant phase of research that present the results of NASA programs and include extensive data or theoretical analysis. Includes compilations of significant scientific and technical data and information deemed to be of continuing reference value. NASA counterpart of peer-reviewed formal professional papers but has less stringent limitations on manuscript length and extent of graphic presentations.

- TECHNICAL MEMORANDUM. Scientific and technical findings that are preliminary or of specialized interest, e.g., quick release reports, working papers, and bibliographies that contain minimal annotation. Does not contain extensive analysis.

- CONTRACTOR REPORT. Scientific and technical findings by NASA-sponsored contractors and grantees.

- CONFERENCE PUBLICATION. Collected papers from scientific and technical conferences, symposia, seminars, or other meetings sponsored or cosponsored by NASA.

- SPECIAL PUBLICATION. Scientific, technical, or historical information from NASA programs, projects, and missions, often concerned with subjects having substantial public interest.

- TECHNICAL TRANSLATION. Englishlanguage translations of foreign scientific and technical material pertinent to NASA's mission.

Specialized services also include creating custom thesauri, building customized databases, organizing and publishing research results.

For more information about the NASA STI program, see the following:

- Access the NASA STI program home page at http://www.sti.nasa.gov

- E-mail your question via the Internet to help@ sti.nasa.gov

- Fax your question to the NASA STI Help Desk at 301-621-0134

- Telephone the NASA STI Help Desk at 301-621-0390

- Write to: NASA Center for AeroSpace Information (CASI) 7115 Standard Drive Hanover, MD 21076-1320 
NASA/TM-2008-215428

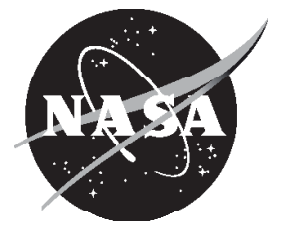

\section{Performance of Subscale Docking Seals Under Simulated Temperature Conditions}

Ian M. Smith and Christopher C. Daniels

The University of Akron, Akron, Ohio

Patrick H. Dunlap and Bruce M. Steinetz

Glenn Research Center, Cleveland, Ohio

Prepared for the

44th Joint Propulsion Conference and Exhibit

cosponsored by the AIAA, ASME, SAE, and ASEE

Hartford, Connecticut, July 21-23, 2008

National Aeronautics and

Space Administration

Glenn Research Center

Cleveland, Ohio 44135 


\section{Acknowledgments}

The authors greatly appreciate the contributions of the JSC LIDS Team for their financial support, Richard Tashjian for his technical support, and of Parker Hannifin Corporation's Composite Sealing Systems

Division (San Diego, CA) for supplying the test articles used in this study.

Trade names and trademarks are used in this report for identification only. Their usage does not constitute an official endorsement, either expressed or implied, by the National Aeronautics and Space Administration.

Level of Review: This material has been technically reviewed by technical management.

Available from

NASA Center for Aerospace Information 7115 Standard Drive

Hanover, MD 21076-1320
National Technical Information Service 5285 Port Royal Road Springfield, VA 22161 


\title{
Performance of Subscale Docking Seals Under Simulated Temperature Conditions
}

\author{
Ian M. Smith and Christopher C. Daniels \\ The University of Akron \\ Akron, Ohio 44325-3901 \\ Patrick H. Dunlap and Bruce M. Steinetz \\ National Aeronautics and Space Administration \\ Glenn Research Center \\ Cleveland, Ohio 44135
}

\begin{abstract}
A universal docking system is being developed by the National Aeronautics and Space Administration (NASA) to support future space exploration missions to low Earth orbit (LEO), to the moon, and to Mars. The candidate docking seals for the system are a composite design consisting of elastomer seal bulbs molded into the front and rear sides of a metal ring. The test specimens were sub-scale seals with two different elastomer cross-sections and a 12-in. outside diameter. The seal assemblies were mated in elastomer seal-on-metal plate and elastomer seal-onelastomer seal configurations. The seals were manufactured from S0383-70 silicone elastomer compound. Nominal and off-nominal joint configurations were examined. Both the compression load required to mate the seals and the leak rate observed were recorded while the assemblies were subjected to representative docking system operating temperatures of $-58,73$, and $122^{\circ} \mathrm{F}\left(-50,23\right.$, and $\left.50^{\circ} \mathrm{C}\right)$. Both the loads required to fully compress the seals and their leak rates were directly proportional to the test temperature.
\end{abstract}

\section{Nomenclature}

$\begin{array}{ll}\text { AO } & \text { atomic oxygen } \\ \text { CVCM } & \text { collected volatile condensable materials } \\ \text { LEO } & \text { low Earth orbit } \\ \text { LIDS } & \text { Low Impact Docking System } \\ \text { MMOD } & \text { micrometeoroid and orbital debris } \\ \text { NASA } & \text { National Aeronautics and Space Administration } \\ \text { RTD } & \text { resistance temperature detector } \\ \text { TML } & \text { total mass loss } \\ \text { UV } & \text { ultraviolet radiation }\end{array}$

\section{Introduction}

NASA is developing a mechanism to connect space vehicles and structures called the Low Impact Docking System (LIDS) (ref. 1). The system is designed to be the interface between pressurized manned and autonomous modules, and to overcome the limitations of docking mechanisms currently in use for the human exploration of space.

The primary advantage of LIDS is the reduced risk associated with the docking operation. The system greatly reduces the load imparted upon the mating structures during docking as compared with other docking mechanisms. Current docking systems rely upon high impact loads and therefore are not being considered for NASA's exploration missions (ref. 2). The reduced load of LIDS minimizes the effect on the activities taking place within the space vehicle or structure (e.g., experiments on the International Space Station) (ref. 3) and enhances the life of the assembly by minimizing structural fatigue. The LIDS is also compact and designed to operate autonomously.

The current design of a LIDS interface employs two functionally different versions of LIDS. One of the two LIDS will be an active docking system while the other will remain passive. The active half of a LIDS-to-LIDS interface contains a main interface seal (see fig. 1). This seal is critical because it confines breathable air inside of the mated vehicles during the mission. Any air lost past the seals must be replaced. The passive half of a LIDS-toLIDS interface provides a smooth flat surface against which the main interface seal docks. However, determining 
the feasibility of having a seal on both halves of a mating interface is of interest. The ability to dock two identical systems would increase the subsystem redundancy and reduce risk for NASA Constellation missions.

When undocked, the LIDS main interface seal will be exposed to the environment in space. Overcoming the synergistic effects of exposure to atomic oxygen (AO), ultraviolet and particle radiation, micrometeoroids, and orbital debris is problematic as the current design of the LIDS does not include any provisions for shielding the main interface seal from the harsh environment when undocked. While in low-Earth orbit (LEO), photodissociation of oxygen's molecular bond occurs between the two oxygen atoms. AO is created and is highly reactive. The exposure of elastomers to $\mathrm{AO}$ can degrade performance depending upon their resistivity to oxidizing

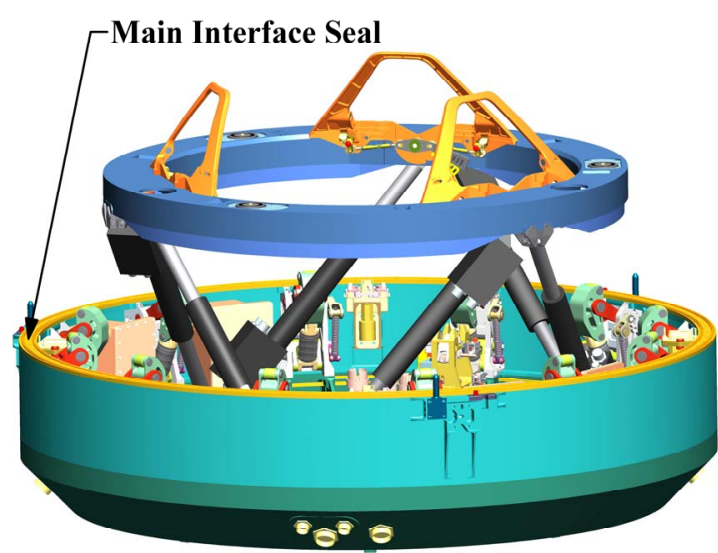

Figure 1.-Illustration of the LIDS. environments (ref. 4). Additionally, the exposure to ultraviolet radiation (UV) from the sun can be a strong contributor to degradation (ref. 4). After excessive exposure to UV, elastomers embrittle and become unusable for seal applications. Collisions by high velocity micrometeoroids and orbital debris (MMOD) are a threat to the seal as well as for the successful operation of the docking system. The current design of LIDS allows for up to 0.025 $\mathrm{lbm} /$ day $(0.011 \mathrm{~kg} /$ day $)$ of air loss through the $58.0 \mathrm{in} .(1.47 \mathrm{~m})$ main interface seal.

The LIDS operating environment includes a range of temperatures to which the system may be exposed while performing NASA Constellation missions. The temperature range of the LIDS severely limits the types of elastomer compounds that can be used to form the seal. Silicone rubber is the only class of elastomer that is commonly molded into seals and has an operating temperature that encompasses expected LIDS exposure temperature $\left(-148\right.$ to $212^{\circ} \mathrm{F}$ $\left(-100\right.$ to $\left.\left.100^{\circ} \mathrm{C}\right)\right)$.

As the LIDS and its main interface seal operate in a vacuum pressure environment, all materials must conform to NASA-STD-(I)-6016 (ref. 5). This standard mandates that outgas byproducts be limited to less than 1.0 percent total mass loss (TML) and less than 0.1 percent collected volatile condensable materials (CVCM) when exposed to heat and vacuum pressures, as tested by ASTM E595-07 (ref. 6). This further limits the number of materials that can be candidates for use in the LIDS seal.

The load required to compress the LIDS main interface seal is an important seal characteristic. Small variations in the elastomer seal geometry have a pronounced effect upon the required load to compress the seal (ref. 7). This is problematic since the manufacturing tolerances of elastomer seals can be relatively large $( \pm 0.005 \mathrm{in} . / 0.01 \mathrm{~cm})$. The capability of the LIDS latch mechanism must be designed to exert enough force to fully compress the seal and to hold the two LIDS together under worst-case loading conditions. However, over design of the latch mechanism adds unnecessary weight to the docking system, space vehicle, and launch system. Therefore, tight manufacturing tolerances must be maintained to ensure the highest seal performance while not causing a significant impact on other docking subsystems. The current design of the LIDS latch mechanism allows for $70 \mathrm{lbf} / \mathrm{in}$. $(120 \mathrm{~N} / \mathrm{cm})$ or less to compress the LIDS main interface seal.

The objectives of the work presented herein were (1) the evaluation of the force required to fully compress the seals, and (2) the quantification of the leak rate. Both of these characteristics were measured at the upper and lower limits of the operating temperature range as well as at ambient temperature. The test specimens used in this study were sub-scale with an outside diameter of approximately $12 \mathrm{in} .(32 \mathrm{~cm})$. The specimens were tested in the asreceived condition without any surface treatments or preconditioning. The performance of each elastomer seal design is presented.

\section{Description of the Experiments}

\section{A. Specimens}

The specimens were Gask-O-Seals manufactured by the Composite Sealing Systems Division at Parker Hannifin Corporation. The first design, referred to as 12 "CBM, consisted of three elastomer seals molded into an aluminum ring as shown in figures 2 and 3. The second design, named the 12"EDU54, consisted of four elastomer 


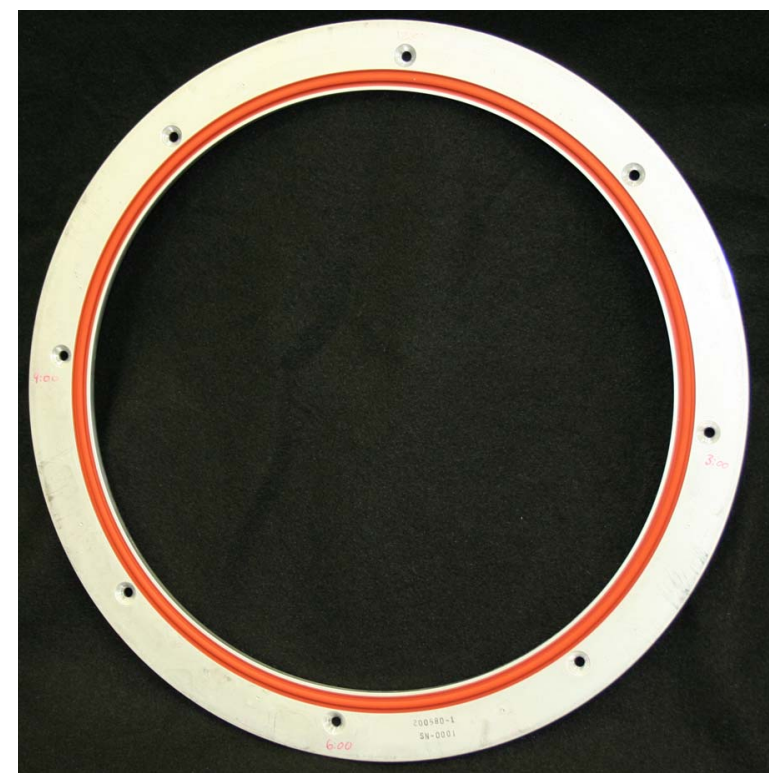

Figure 2.-Photograph of a 12"CBM test specimen showing the front side with a single elastomer seal.

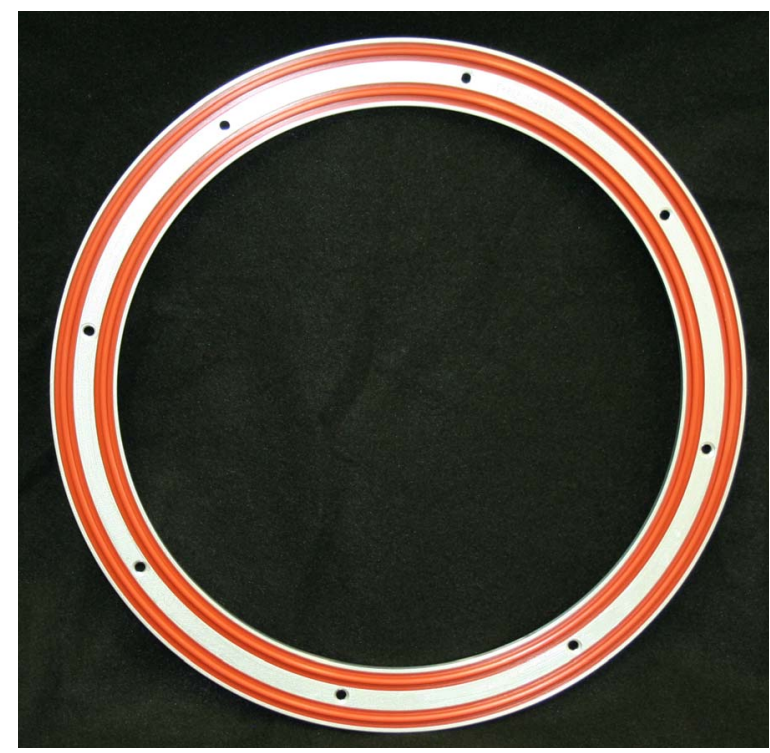

Figure 4.-Photograph of a 12"EDU54 test specimen showing the front side with two elastomer seals.

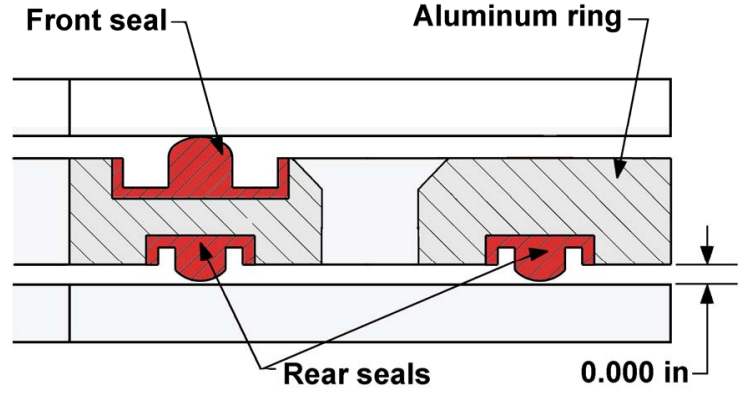

Figure 3.--Illustration of the cross-section of a 12"CBM test specimen having one front-side and two rear-side elastomer seals in the aluminum ring.

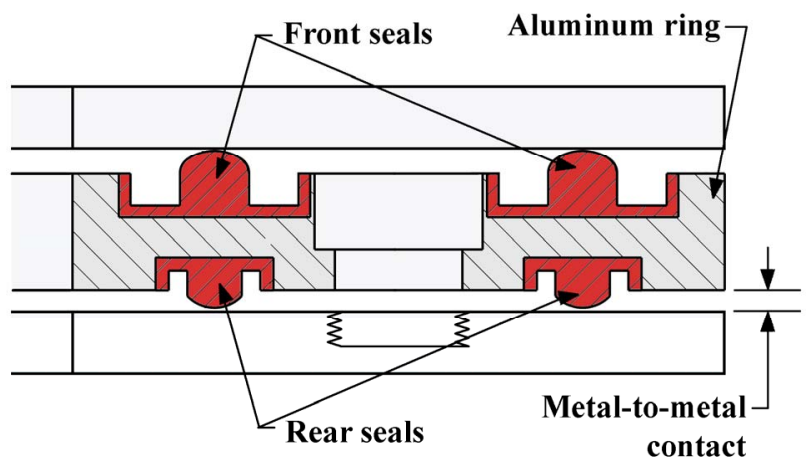

Figure 5.-Illustration of the cross-section of a 12"EDU54 test specimen having two front-side and two rear-side elastomer seals in the aluminum ring.

seals molded into a similar aluminum ring as shown in figures 4 and 5. For both designs, the elastomer seals were made of silicone compound S0383-70, manufactured by Parker Hannifin Corporation. The outside diameter and thickness of the 6061-T651 aluminum rings were 12.0 in. $(30.5 \mathrm{~cm})$ and $0.20 \mathrm{in} .(0.51 \mathrm{~cm})$, respectively.

The elastomer seals were vacuum molded into both the top and bottom surfaces of the aluminum ring to prevent leakage through the interface. The cross-sections of the elastomer seals within the metal ring are proprietary designs and will be described only in general terms. The cross-sections of the seals on the rear side of both designs were 
identical, but were different from those on the front side. The front side of the 12" $\mathrm{CBM}$ had one circumferential elastomer seal, while the 12"EDU54 had two similar cross-section elastomer seals. The cross-sections of the frontside 12"CBM and 12"EDU54 elastomer seals differed only in the width of the sealing surface. The sealing surfaces on the front-side 12"EDU54 elastomer seals were $0.006 \mathrm{in} .(0.015 \mathrm{~cm})$ narrower than that of the single front-side 12 "CBM elastomer seal.

The elastomer used to manufacture all of the seals presented in this study was silicone compound S0383-70. This silicone elastomer compound has been shown to be durable when exposed to simulated LIDS operating environments (ref. 4). The elastomer compound was tested per ASTM E595 (ref. 6) to verify that the amount of volatiles contained within the test specimens was below the required limits of 1.0 and 0.1 percent for TML and CVCM, respectively (ref. 8).

When assembled onto the test apparatus, the aluminum ring was fastened against the stainless steel test fixture using eight equally spaced fasteners so that the rear seals were fully compressed. The crown heights of the front and rear seals were nominally 0.040 in. $(1.0 \mathrm{~mm})$ and 0.023 in. $(0.58 \mathrm{~mm})$, respectively, above the surrounding aluminum ring.

The elastomers were tested in their as-received, untreated condition. They were not exposed to any constituents of space environments, including AO, UV, ionizing radiation, MMOD impacts, or vacuum pressure. After being installed onto the test fixtures, the specimens were cleaned using isopropyl alcohol and air dried for 5 min prior to testing.

\section{B. Temperature control system}

The temperature of the seal specimens was controlled during testing using an Instron 3119-407 environmental control system. The test specimens were installed onto the compression test fixture or leak rate measurement system, located inside of the environmental control chamber, while at room temperature. The desired test temperature was programmed into the environmental control system, and the temperatures of the specimens were monitored using a resistance temperature detector (RTD) mounted directly to the test fixture. The RTD had an accuracy of $0.18{ }^{\circ} \mathrm{F}$ $\left(0.10{ }^{\circ} \mathrm{C}\right)$. The test began once the desired temperature was achieved. During the tests, the temperature was maintained within $0.9^{\circ} \mathrm{F}\left(0.5^{\circ} \mathrm{C}\right)$

\section{Compression test system}

The force required to compress the front-side seals was determined using an Instron Model 5584 electromechanically actuated material test system. The test specimens were attached to the load frame using stainless steel platens (fig. 6). Each platen was attached to the load frame actuator rods using one coaxially located threaded stud. The test specimens were coaxially aligned with the centerline of the load frame and attached to the platens using eight equally spaced fasteners.

The seal specimens were assembled in either of two configurations: (a) elastomer seal against a flat plate, or (b) elastomer seal against elastomer seal. When tested in elastomer seal-on-elastomer seal configuration, the test specimens were mated so that the crowns of the mating seals landed directly on top of each other (i.e., the seals were aligned coaxially with the load frame and each other). This is shown in figures 7 and 8 . When tested in elastomer seal-on-metal plate configuration, the seal test specimens were mounted on the lower platen and compressed against the upper platen which had a surface finish of better than $16 \mu$ in. $(0.4 \mu \mathrm{m})$. This is shown in figures 3 and 5 .

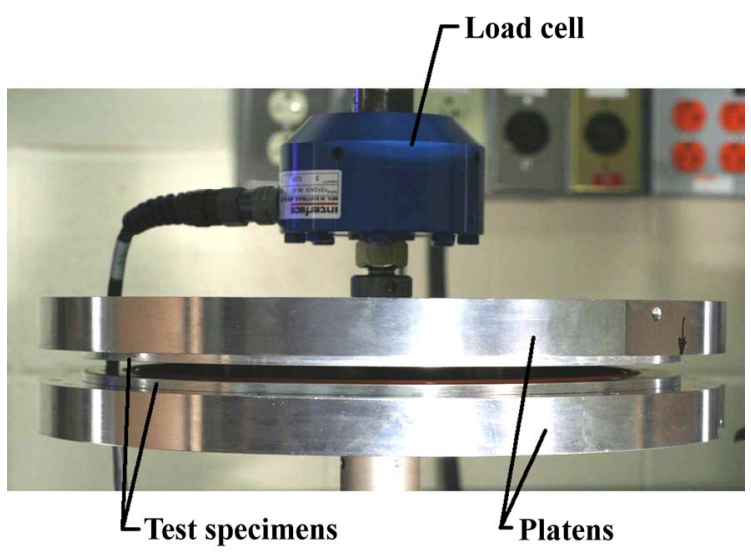

Figure 6.-Photograph of the compression test system with installed platens and seal specimens. 


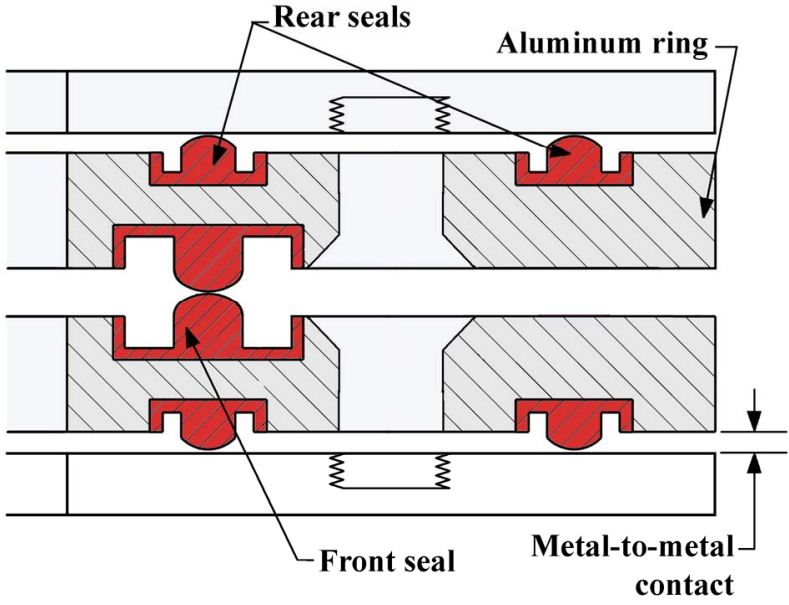

Figure 7.-Illustration of the cross-section of 12"CBM test specimens configured in an elastomer seal-onelastomer seal assembly.

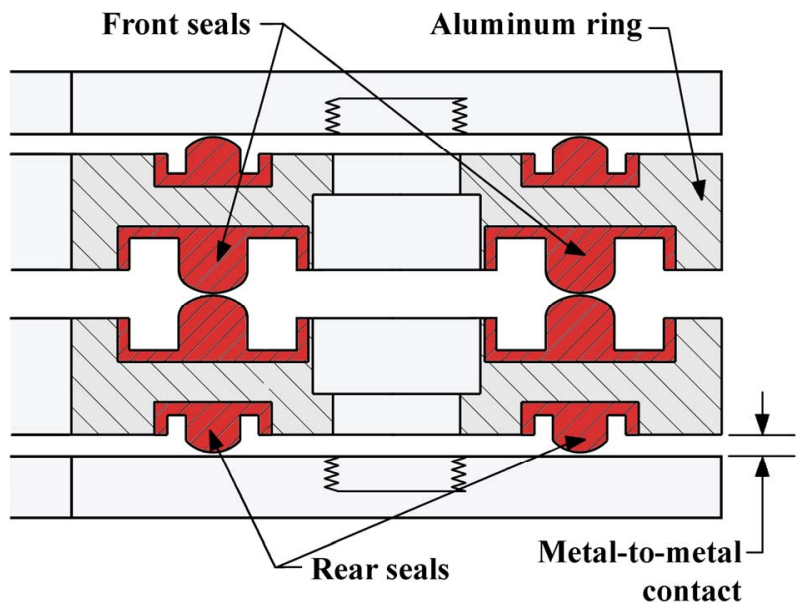

Figure 8.-Illustration of the cross-section of 12"EDU54 test specimens configured in an elastomer seal-onelastomer seal assembly.

A precision gauge was used to set the distance between the mating surfaces prior to the start of the test. The distance between the upper and lower assemblies was reduced until their contact surfaces were fully compressed against one another. The speed at which the two assemblies approached one another was not constant, but was a function of time as shown in figure 9. This loading profile simulated the rate at which two LIDS approach each other during docking.

During the compression stroke, the force required to compress the seals was measured using an Instron 2525-171 load cell with an accuracy of \pm 0.25 percent of the reading. The upper and lower assemblies were compressed together until $6000 \mathrm{lbf}(27000 \mathrm{~N})$ compression force was recorded.

The force required to compress the seal assemblies was determined by searching the data set for the displacement corresponding to the initial distance between the two contacting surfaces. This distance was set using the precision gauge prior to the test and was defined as the starting point for the loading profile. For tests conducted above or below room temperature, corrections were made to account for the thermal expansion of the test fixtures.

Previous studies (ref. 8) have shown that compression load results can be greatly affected by the number of compression cycles an elastomer seal test specimen experiences. The elastomer softens with each compression cycle and the force required to compress the seals decreases. The results presented herein are of test specimens that have been compressed several times prior to compression testing.

\section{Leak rate measurement system}

The leak rate of each seal configuration was quantified using a pressure decay system. The system measured any mass loss across the seal specimen(s), including the amount of dry air that passed through any leakage paths (e.g., through microcracks and at the interface between the sealing interfaces) and permeated through the specimens' elastomer compound.

The system consisted of a gas reservoir, with a known volume, that was immersed in a water bath to moderate any temperature fluctuation of the gas within the closed system (fig. 10). The temperature of the water was monitored by an RTD with an accuracy of $\pm 0.35{ }^{\circ} \mathrm{F}\left(0.20^{\circ} \mathrm{C}\right)$. Dry air was supplied to the gas reservoir at $14.7 \mathrm{psig}(101 \mathrm{kPa})$. The pressure in the gas reservoir was monitored using two pressure transducers. The pressure transducers provided 0.05 percent full-scale accuracy over a range of 0 to $20 \mathrm{psig}$ ( 0 to $140 \mathrm{kPa}$ ). The gas reservoir was connected to the test section containing the test specimen, as shown in figure 11 .

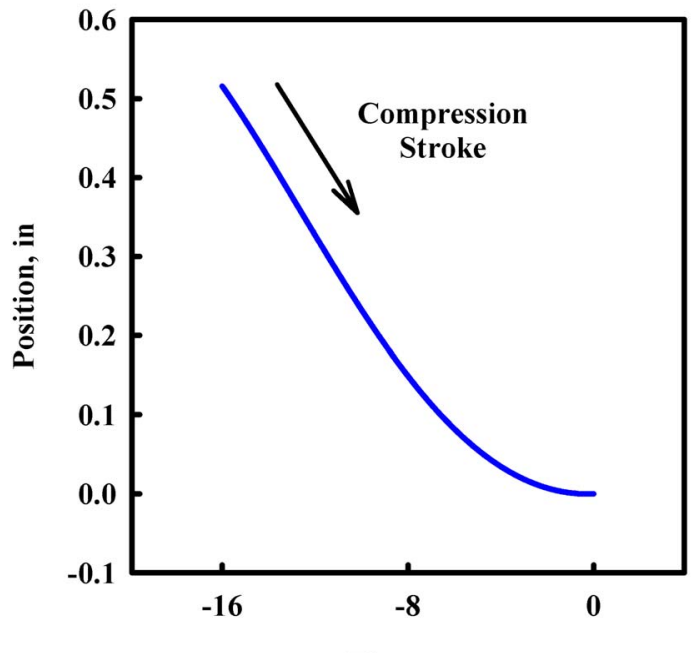

Time, sec

Figure 9.-Compression test closure rate. 


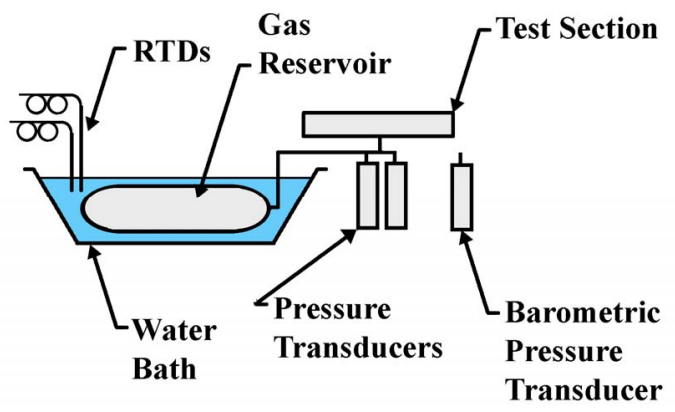

Figure 10.-Illustration of the pressure decay leak rate measurement system.

The seal specimens were assembled in either of two configurations: (a) elastomer seal against a flat plate, or (b) elastomer seal against elastomer seal. The surface finish of the test apparatus was better than $16 \mu$ in. $(0.4 \mu \mathrm{m})$. The seals were coaxially aligned, mated, and compressed until their aluminum rings were fully compressed against one another, thus producing an ideal mating configuration. The test gas (i.e., dry air) was supplied to the interior of the mated seals at a pressure of $14.7 \mathrm{psig}(101 \mathrm{kPa})$. Subsequent tests investigated leak rates of non-ideal mating configurations. In these investigations, the aluminum rings of the mated seals were not fully compressed together. Instead, calibrated spacers were placed between the aluminum rings so that a uniform, defined gap was obtained and the elastomer seals were in contact, but not fully compressed.

The pressure decay system quantified the mass of gas within the system over time. To quantify the amount of gas within the system, gas pressure and temperature were monitored. Assuming an ideal gas, mass was calculated from the following equation:

$$
m=\frac{p V}{R T}
$$

where $m$ was the mass of the gas within the leakage quantification system, $V$ was the closed volume, $p$ was absolute gas pressure, and $T$ was temperature. The system mass was calculated every $10 \mathrm{sec}$ and a line was fit to the collection of mass points. The slope of the best fit line provided the specimen leak rate. The duration of each test was a minimum of $22 \mathrm{hr}$, but some tests were allowed to run as long as 3 days in order to reach steady state conditions due to low permeation through the elastomer compound.

To ensure that the system of the supply lines from the gas reservoir to the test section was hermetic, the system was checked with a helium leak detection system and was found to leak no greater than $2.5 \times 10^{-9} \mathrm{lbm} /$ day $\left(1.1 \times 10^{-9} \mathrm{~kg} /\right.$ day $)$. Hence, any decrease in the mass of gas within the closed system was attributable to the test specimen leakage.

The data from two time steps was used to compute the error of the measurement, using the following equation:

$$
\dot{m} \approx \frac{\Delta m}{\Delta t}=\frac{V}{R \cdot \Delta t}\left(\frac{p_{1}}{T_{1}}-\frac{p_{2}}{T_{2}}\right)
$$

The subscripts denote two time steps (i.e., the beginning and end of the test). An uncertainty analysis was used to produce the error bars shown in the results graphs. The uncertainty analysis of eq. (2) resulted in eq. (3), 
$u_{\dot{m}}=\dot{m}\left\{\left(\frac{u_{V}}{V}\right)^{2}+\left(u_{p_{1}} \frac{T_{2}}{P_{1} T_{2}-P_{2} T_{1}}\right)^{2}+\left(u_{p_{2}} \frac{T_{1}}{P_{1} T_{2}-P_{2} T_{1}}\right)^{2}+\left(u_{T_{1}} \frac{P_{1} T_{2}}{T_{1}\left(P_{1} T_{2}-P_{2} T_{1}\right)}\right)^{2}+\left(u_{T_{2}} \frac{P_{2} T_{1}}{T_{2}\left(P_{1} T_{2}-P_{2} T_{1}\right)}\right)^{2}\right\}^{1 / 2}$

where $u$ represents the uncertainty for the subscripted variable. Similar to eq. (2), the numeric subscripts denote two time steps (i.e., the beginning and end of the test). Uncertainties for each variable within the equation, including calibration error, were estimated and combined using the root-sum-square method. Leak rate uncertainty was computed for each individual specimen trial. Due to the variation in the pressure measurements for each individual trial (and less for temperature variability), the size of the leak rate error bars was different for each data point plotted.

\section{Experimental Results and Discussion}

\section{A. Compression tests}

The load required to compress both the 12"CBM and 12"EDU54 test specimens was determined at each of three temperatures, $-58,73$, and $122{ }^{\circ} \mathrm{F}\left(-50,23\right.$, and $\left.50{ }^{\circ} \mathrm{C}\right)$. The force required to compress the seals was quantified when the seals were mated in elastomer seal-on-elastomer seal and elastomer seal-on-metal plate configurations. The compression level was continuously increased according to the displacement-time curve of figure 9 . The force reported in figure 12 was the load required to compress the seal(s) to the point of full metal-to-metal contact, including compensation for temperature as described in section II.C.

The loads required to compress the 12 " $\mathrm{CBM}$ seal test specimens in elastomer seal-on-metal plate and elastomer seal-on-elastomer seal were $82.9 \mathrm{lbm} / \mathrm{in} .(145 \mathrm{~N} / \mathrm{cm})$ and $58.6 \mathrm{lbm} / \mathrm{in} .(103 \mathrm{~N} / \mathrm{cm})$ at room temperature, respectively. When the test temperature was increased to $122^{\circ} \mathrm{F}\left(50{ }^{\circ} \mathrm{C}\right)$, the required force increased by 2.9 percent to 85.4 $\mathrm{lbm} /$ in. $(150 \mathrm{~N} / \mathrm{cm})$ for the elastomer seal-on-metal plate configuration and $59.6 \mathrm{lbm} / \mathrm{in}$. $(104 \mathrm{~N} / \mathrm{cm})$ for the elastomer seal-on-elastomer seal configuration. When the test temperature was reduced to $-58^{\circ} \mathrm{F}\left(-50^{\circ} \mathrm{C}\right)$, the force required to fully compress the seals also decreased. At $-58{ }^{\circ} \mathrm{F}\left(-50{ }^{\circ} \mathrm{C}\right)$, the elastomer seal-on-metal plate and elastomer seal-on-elastomer seal configurations required $77.8 \mathrm{lbm} / \mathrm{in}$. $(136 \mathrm{~N} / \mathrm{cm})$ and $51.8 \mathrm{lbm} / \mathrm{in} .(90.7 \mathrm{~N} / \mathrm{cm})$, respectively, to compress the seals.

The 12"EDU54 seal test specimens were also evaluated when assembled in elastomer seal-on-metal plate and elastomer seal-on-elastomer seal configurations. At room temperature, $62.9 \mathrm{lbm} / \mathrm{in}$. $(110 \mathrm{~N} / \mathrm{cm})$ and $35.9 \mathrm{lbm} / \mathrm{in}$. $(62.9 \mathrm{~N} / \mathrm{cm})$, respectively, were required to fully compress the seals. The force to compress the seals increased to 65.2 $\mathrm{lbm} / \mathrm{in} .(114 \mathrm{~N} / \mathrm{cm})$ and $37.5 \mathrm{lbm} / \mathrm{in} .(65.6 \mathrm{~N} / \mathrm{cm})$ when the test temperature was raised to $122^{\circ} \mathrm{F}\left(50^{\circ} \mathrm{C}\right)$, representing a respective 3.8 and 4.1 percent increase over room temperature measurements. When the seals were refrigerated to $-58^{\circ} \mathrm{F}\left(-50^{\circ} \mathrm{C}\right)$, the elastomer seal-on-metal plate and elastomer seal-on-elastomer seal configurations required $57.5 \mathrm{lbm} / \mathrm{in}$. (101 N/cm) and $34.5 \mathrm{lbm} / \mathrm{in}$. (60.4 $\mathrm{N} / \mathrm{cm}$ ), respectively.

In every instance, the load required to compress the seal assemblies in an elastomer seal-on-elastomer seal configuration was lower than that of an elastomer seal-onmetal plate configuration. This reduction was as much as 43 percent for the 12"EDU54 seal at room temperature. This characteristic is attributable to the boundary condition of the seals' interface surface. When the seal interacts with a metal plate, friction inhibits the elastomer from moving in the radial direction. This behavior confines the elastomer causing an increase in seal reaction force. In the elastomer seal-on-elastomer seal configurations, the interface surfaces of both seals interact with a replicate seal. The interaction

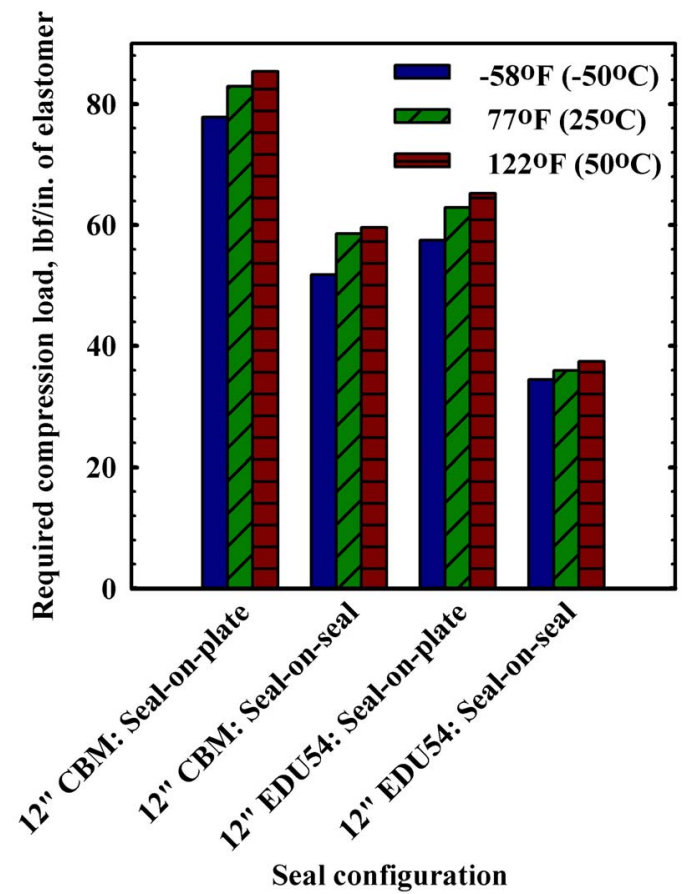

Figure 12.-Compression test results for 12 "CBM and 12 "EDU54 seals at various temperatures. 
closely models that of a frictionless surface and allows radial motion of the elastomer during the compression, which reduces the force required to compress the seal.

The variation in force required to fully compress the seals above or below room temperature was attributed to the relative volume change of the seal and ring due to the differences in each material's coefficient of thermal expansion (see table 1). The coefficient of thermal expansion of the S0383-70 elastomer $\left(197 \mu \mathrm{in} . / \mathrm{in} .-^{\circ} \mathrm{F}\right.$ or $\left.355 \mu \mathrm{m} / \mathrm{m}-{ }^{\circ} \mathrm{C}\right)(\mathrm{ref}$. $7)$ is much greater than that of the aluminum ring $\left(12.7 \mu \mathrm{in} . / \mathrm{in} .-^{\circ} \mathrm{F}\right.$ or $\left.22.9 \mu \mathrm{m} / \mathrm{m}-{ }^{\circ} \mathrm{C}\right)(\mathrm{ref}$. 9). This difference further confines the elastomer seal(s) at an increased test temperature and results in an elevated force necessary to fully compress the seals.

TABLE 1.-COEFFICIENTS OF THERMAL EXPANSION

\begin{tabular}{|c|c|}
\hline Material & $\begin{array}{c}\text { Coefficient of thermal expansion } \\
\left(\mu \mathrm{in} . / \mathrm{in} .{ }^{\circ} \mathrm{F} / \mu \mathrm{m} / \mathrm{m}-{ }^{\circ} \mathrm{C}\right)\end{array}$ \\
\hline Silicone S0383-70 & $197 / 355$ \\
\hline Aluminum 6061-T651 & $12.7 / 22.9$ \\
\hline
\end{tabular}

\section{B. Leak Rate Measurements}

\section{Temperature Effects on Leak Rates of Single and Mated Pairs of 12"CBM and 12"EDU54 Seals}

The leak rate of both the 12"CBM and 12"EDU54 test specimens was determined at each of three temperatures: $-58,73$, and $122^{\circ} \mathrm{F}\left(-50,23\right.$, and $\left.50^{\circ} \mathrm{C}\right)$. The leak rate was quantified when the seals were mated in elastomer sealon-elastomer seal and elastomer seal-on-metal plate configurations (see fig. 13). Additionally, the leak rates corresponding to various misaligned configurations were examined, including cases where (a) the seals were not completely compressed, and (b) elastomer seal-on-elastomer seal bulbs were not coaxial. Replicate tests were conducted by removing the test specimens from the test fixtures and allowing the seals to recover for a minimum of $5 \mathrm{~min}$ before reassembly. When numeric values are presented in this section, the value represents the arithmetic average of the trials in the described assembly configuration.

The values reported herein are presented in units of $\mathrm{lbm} / \mathrm{in} . / \mathrm{day}(\mathrm{kg} / \mathrm{cm} /$ day $)$. The length represents the elastomer seal centerline circumferential length of the innermost elastomer seal, so that the results can be scaled to predict leak rates for seals of other sizes. When the maximum allowable leak rate value $\left(2.5 \times 10^{-3} \mathrm{lbm} / \mathrm{day}\left(1.1 \times 10^{-3} \mathrm{~kg} / \mathrm{day}\right)\right)$ for the $58.0 \mathrm{in}$. $(1.47 \mathrm{~m})$ LIDS main interface seal is scaled to the $12.0 \mathrm{in}$. $(30.5 \mathrm{~cm})$ sub-scale seals used in this study, the sub-scale maximum allowable leak rate value is $4.6 \times 10^{-4} \mathrm{lbm} /$ day $\left(2.1 \times 10^{-4} \mathrm{~kg} /\right.$ day $)$.

The leak rate of the 12"CBM test specimens was measured when the seal(s) was assembled in elastomer seal-onelastomer seal and elastomer seal-on-metal plate configurations. At room temperature, the leak rate of the elastomer seal-on-elastomer seal configuration was slightly higher, $1.58 \times 10^{-6} \mathrm{lbm} / \mathrm{in}$. $/$ day $\left(2.82 \times 10^{-7} \mathrm{~kg} / \mathrm{cm} / \mathrm{day}\right)$, than that for the elastomer seal-on-metal plate configuration, $6.75 \times 10^{-7}$ $\mathrm{lbm} / \mathrm{in} . /$ day $\left(1.21 \times 10^{-7} \mathrm{~kg} / \mathrm{cm} /\right.$ day $)$. The test temperature influenced the leak rate of both assembly configurations. Raising the test temperature from room temperature to $122^{\circ} \mathrm{F}$ $\left(50{ }^{\circ} \mathrm{C}\right)$ increased the leak rate by 47 percent to $2.33 \times 10^{-6}$ $\mathrm{lbm} /$ in./day $\left(4.18 \times 10^{-7} \mathrm{~kg} / \mathrm{cm} /\right.$ day $)$ for the elastomer seal-onelastomer seal configuration. Lowering the test temperature decreased the leak rate by 35 percent to $1.03 \times 10^{-6} \mathrm{lbm} / \mathrm{in}$./day $\left(1.85 \times 10^{-7} \mathrm{~kg} / \mathrm{cm} /\right.$ day $)$ for this configuration.

The leak rate of the 12"EDU54 test specimens was quantified only when configured in an elastomer seal-on-metal plate configuration. At room temperature, the leak rate was quantified as $2.33 \times 10^{-7} \mathrm{lbm} / \mathrm{in}$./day $\left(4.16 \times 10^{-8} \mathrm{~kg} / \mathrm{cm} /\right.$ day $)$. This value was 66 percent lower than the 12 " $\mathrm{CBM}$ seal in the same configuration. However, much of the improved leak rate is attributable to the addition of the second front-side seal in the 12"EDU54 design. A 40 percent increase in leak rate to $3.26 \times 10^{-7} \mathrm{lbm} /$ in./day $\left(5.84 \times 10^{-8}\right.$ $\mathrm{kg} / \mathrm{cm} /$ day) was observed when the test temperature was increased to $122{ }^{\circ} \mathrm{F}\left(50^{\circ} \mathrm{C}\right)$. The leak rate was decreased by

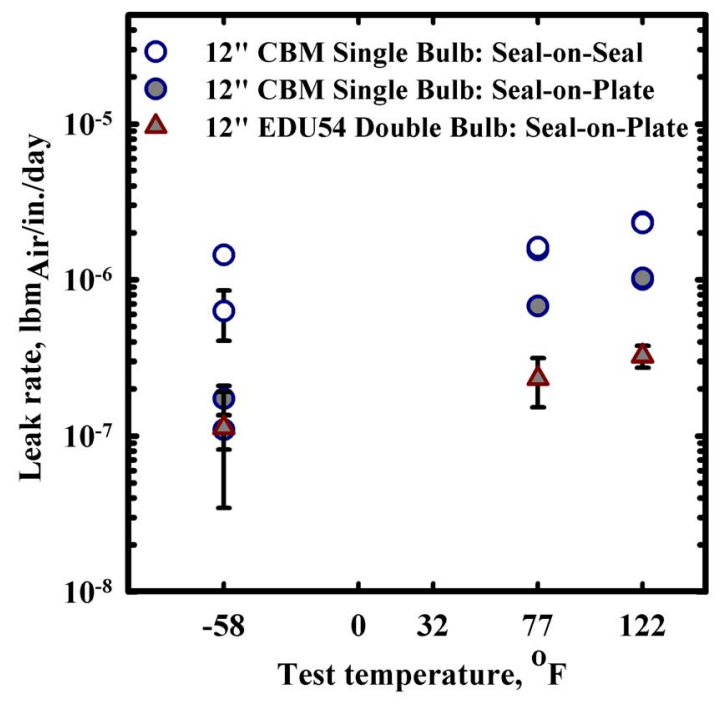

Figure 13.-Leak rate performance of 12 "CBM and 12 "EDU54 seals at various temperatures. 
52 percent to $1.13 \times 10^{-7} \mathrm{lbm} / \mathrm{in}$./day $\left(2.02 \times 10^{-8} \mathrm{~kg} / \mathrm{cm} /\right.$ day $)$ when the test temperature was lowered to $-58^{\circ} \mathrm{F}\left(-50^{\circ} \mathrm{C}\right)$.

The correlation between test temperature and leak rate is attributable to the change in density of the elastomer compound. At an increased temperature, the volume of the elastomer increases due to the coefficient of thermal expansion. The permeation of gas through the elastomer also increases. The opposite is observed when the temperature of the elastomer is reduced.

\section{Incomplete Compression Effects on Single and Mated Pairs of 12"CBM and 12"EDU54 Seals}

At room temperature, the leak rate of a single seal and pairs of mated 12"CBM and 12"EDU54 seals were quantified when the mating metal seal surfaces were not fully compressed (see fig. 14). The distance between the metal surfaces was increased incrementally from fully compressed (distance equals 0 ) until a dramatic increase in leak rate was observed. When the distance between the mating surfaces was increased to the point that the leak rate increased significantly, the seal lost its sealing effectiveness and no further testing was conducted.

To compare seal designs, the outer seal of the 12"EDU54 test specimen was bypassed so that both seals had only one useful front-side seal.

When the seals were assembled in an elastomer seal-on-metal plate configuration, the 12"CBM seal showed a marked increase in leak rate when the distance between the seal and the interfacing metal plate was $0.030 \mathrm{in} .(0.076$ $\mathrm{cm})$. At this distance, the leak rate increased by 840 percent from $7.68 \times 10^{-7} \mathrm{lbm} / \mathrm{in} . /$ day $\left(1.37 \times 10^{-7} \mathrm{~kg} / \mathrm{cm} / \mathrm{day}\right)$ when fully compressed to $7.23 \times 10^{-6} \mathrm{lbm} / \mathrm{in}$./day $\left(1.29 \times 10^{-6} \mathrm{~kg} / \mathrm{cm} /\right.$ day $)$ as the compression on the elastomer seal neared zero. The 12"EDU54 seal showed a similar trend, though the marked increase in leak rate occurred at a greater displacement between the interfacing surfaces. At 0.045 in. $(0.11 \mathrm{~cm})$ standoff distance, the seals were not in contact and could not be tested.

When the seals were configured in elastomer seal-on-elastomer seal assemblies, the seals were far more tolerant of incomplete compression, as would be expected. The 12" $\mathrm{CBM}$ seals showed little increase in leak rate with increasing distance between the mating surfaces until the seals were separated by approximately $0.060 \mathrm{in} .(0.15 \mathrm{~cm})$. At that distance, the leak rate increased from $1.26 \times 10^{-6} \mathrm{lbm} / \mathrm{in} . /$ day $\left(2.24 \times 10^{-7} \mathrm{~kg} / \mathrm{cm} / \mathrm{day}\right)$ at full compression to $1.41 \times 10^{-5} \mathrm{lbm} / \mathrm{in}$./day $\left(2.51 \times 10^{-6} \mathrm{~kg} / \mathrm{cm} /\right.$ day $)$. The $12^{\prime \prime}$ EDU54 seals exhibited a similar level of leak rate and a similar trend as the 12 " $\mathrm{CBM}$, though the sealing effectiveness was maintained to a standoff distance of $0.075 \mathrm{in}$. $(0.19 \mathrm{~cm})$. The seals lost their effectiveness only when separated by 0.080 in. $(0.20 \mathrm{~cm})$.

Results showed that very little seal engagement is required to form an adequate seal. This is further evidence that the sealing capabilities of these designs are dominated by permeation through the material, rather than by leak paths at the elastomer seal-to-metal plate or elastomer seal-to-elastomer seal interfaces.

The shape of the elastomer seal-on-elastomer seal and elastomer seal-on-metal plate curves in figure 12 is different. The seal-on-plate curves show a steady increase in leak rate with increased distance between the mating surfaces whereas the seal-on-seal curves show an approximately level leak rate with distance indicating more tolerance to incomplete compression.

\section{Axial misalignment effects on mated pairs of 12"CBM and 12"EDU54 seals}

The leak rate of mated pairs of both 12"CBM and 12"EDU54 seals were quantified at various levels of axial misalignment (see fig. 15). The axes of the seal pairs were intentionally displaced in discrete levels upon assembly until the sealing effectiveness was lost. 
Both of the seal designs, 12"CBM and 12"EDU54, exhibited similar performance at each of the discrete increments of axial misalignment, including 0.000 , $0.060,0.080,0.100,0.120$, and 0.150 in. $(0.00,0.15$, $0.20,0.254,0.305$, and $0.381 \mathrm{~cm}$ ). The seal leak rates were approximately constant until assembled with an axial offset of $0.150 \mathrm{in} .(0.381 \mathrm{~cm})$. At this level of axial misalignment, the leak rates of the 12 "CBM increased from $1.26 \times 10^{-6} \mathrm{lbm} /$ in. $/$ day $\left(2.24 \times 10^{-7} \mathrm{~kg} / \mathrm{cm} /\right.$ day $)$ when ideally aligned to $1.72 \times 10^{-5} \mathrm{lbm} / \mathrm{in}$./day $\left(3.07 \times 10^{-6}\right.$ $\mathrm{kg} / \mathrm{cm} /$ day). The 12 "EDU54 test specimen would not seal with a 0.150 in. $(0.381 \mathrm{~cm})$ axial misalignment.

\section{Conclusion}

The compression load and leak rate characteristics of two candidate sub-scale LIDS main interface seal designs were evaluated and quantified. Two assembly configurations, elastomer seal-on-elastomer seal and elastomer seal-on-metal plate, were examined at three test temperatures: $-58,73$, and $122{ }^{\circ} \mathrm{F}(-50,23$, and $\left.50{ }^{\circ} \mathrm{C}\right)$.

The loads required to compress the 12 " $\mathrm{CBM}$ seal test specimens in elastomer seal-on-metal plate and elastomer seal-on-elastomer seal were $82.9 \mathrm{lbm} / \mathrm{in} .(145 \mathrm{~N} / \mathrm{cm})$ and $58.6 \mathrm{lbm} / \mathrm{in} .(103 \mathrm{~N} / \mathrm{cm})$ at room temperature, respectively. The corresponding values of compression force for the 12"EDU54 seal test specimens were $62.9 \mathrm{lbm} / \mathrm{in} .(110 \mathrm{~N} / \mathrm{cm})$ and $35.9 \mathrm{lbm} / \mathrm{in} .(62.9 \mathrm{~N} / \mathrm{cm})$, respectively. For both candidate seal designs at all test temperatures, the load required to compress the seal assemblies in an elastomer seal-on-metal plate configuration was higher than that of an elastomer seal-on-elastomer seal configuration. Increasing the temperature of both seal designs raised the load required to compress the seals.

At all test temperatures, the 12"EDU54 seal was fully compressed in both elastomer seal-on-elastomer seal and elastomer seal-on-metal plate configurations with less than the LIDS main interface seal allocation of $70 \mathrm{lbf} / \mathrm{in}$ $(120 \mathrm{~N} / \mathrm{cm})$. The 12"CBM seal exceeded the limit when assembled in elastomer seal-on-metal plate configurations at all test temperatures, but met the goal when configured elastomer seal-on-elastomer seal.

The leak rate of the 12" $\mathrm{CBM}$ seal assembled in an elastomer seal-on-elastomer seal configuration was slightly higher, $1.58 \times 10^{-6} \mathrm{lbm} / \mathrm{in}$./day $\left(2.82 \times 10^{-7} \mathrm{~kg} / \mathrm{cm} / \mathrm{day}\right)$, than that for the elastomer seal-on-metal plate configuration, $6.75 \times 10^{-7} \mathrm{lbm} / \mathrm{in}$./day $\left(1.21 \times 10^{-7} \mathrm{~kg} / \mathrm{cm} / \mathrm{day}\right)$, at room temperature. The leak rate of the 12"EDU54 was $2.33 \times 10^{-7} \mathrm{lbm} / \mathrm{in}$./day $\left(4.16 \times 10^{-8} \mathrm{~kg} / \mathrm{cm} /\right.$ day $)$ at room temperature. For all seal designs and assembly configurations, the leak rate was shown to rise with an increased test temperature.

The effect of incomplete seal compression on leak rate was examined. For both candidate seal designs, the elastomer seal-on-metal plate configuration showed an elevated leak rate with increased distance between the mating surfaces, whereas the elastomer seal-on-elastomer seal configuration showed a level leak rate with distance indicating more tolerance to incomplete compression.

When each of the two seal designs were axially misaligned in elastomer seal-on-elastomer seal configurations, the axial misalignment of the two mating seals had little effect until the misalignment reached a critical level of 0.150 in. $(0.381 \mathrm{~cm})$.

When fully compressed, both the 12"CBM and the 12"EDU54 seals at all test temperatures met the scaled leak rate goal allocated to the LIDS main interface seal $\left(1.4 \times 10^{-5} \mathrm{lbm} / \mathrm{in}\right.$./day) in both elastomer seal-on-elastomer seal and elastomer seal-on-metal plate configurations. Only when the distance between the mating surfaces was increased to within 0.005 in. $(0.1 \mathrm{~mm})$ of the combined bulb height (elastomer seal-on-elastomer seal and elastomer seal-on-metal plate configurations) or axially misaligned by 0.150 in. $(3.8 \mathrm{~mm})$ (elastomer seal-on-elastomer seal configuration) did the seals not meet the leak rate goal. 


\section{References}

1. Lewis, J.L., Carroll, M.B., Morales, R.H., Le, T.D., National Aeronautics and Space Administration, Washington, DC, "Androgynous, reconfigurable closed loop feedback controlled low impact docking system with load sensing electromagnet capture system," U.S. Patent No. 6354540, (2002).

2. Zimpfer, D., Kachmar, P, and Tuohy, S., "Autonomous rendezvous, capture and in-space assembly: past, present and future", 1st Space Exploration Conference, Orlando, FL, 2005.

3. Ringelberg, J., "Alignment, capture and mate (ACM) docking system development for space exploration," IEEEAC paper \#1538, ver. 2, Nov. 1, 2005.

4. Daniels, C., de Groh III, H., Dunlap, P., Finkbeiner, J., Steinetz, B., Bastrzyk, M., Oswald, J., Banks, B., Dever, J., Miller, S., and Waters, D., "Characteristics of elastomer seals exposed to space environments," 43rd AIAA/ASME/SAE/ASEE Joint Propulsion Conference \& Exhibit, AIAA-2007-5741, Cincinnati, OH.

5. NASA-STD-(I)-6016, "Standard materials and processes requirements for spacecraft," National Aeronautics and Space Administration, expires Sept. 2007.

6. ASTM E595-07 (Reapproved 2003), "Standard test method for total mass loss and collected volatile condensable materials from outgassing in a vacuum environment," ASTM International.

7. Oswald, J., Daniels, C., Dunlap, P., and Steinetz, B., "Simulating leakage and stiffness of seals for a low impact docking system," AIAA SPACE 2007 Conference \& Exposition, AIAA-2007-6206, Long Beach, CA.

8. Daniels, C.C., Oswald, J., Smith, I., Bastrzyk, M.B., Dunlap, P.H, \& Steinetz B.M., "Experimental investigation of elastomer docking seal compression set, adhesion and leakage," AIAA Space 2007 Conference and Exposition, AIAA-2007-6197, Long Beach, CA.

9. MIL-HDBK-5H, "Metallic Materials and Elements for Aerospace Vehicle Structures (Knovel Interactive Edition)," U.S. Department of Defense, 2003. 


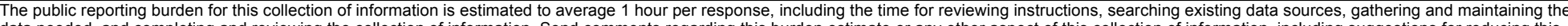

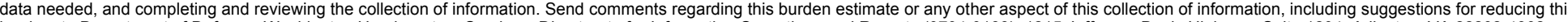

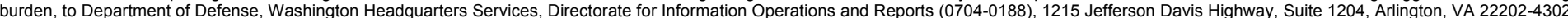

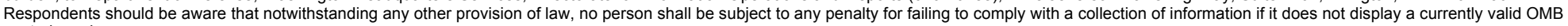
control number.

PLEASE DO NOT RETURN YOUR FORM TO THE ABOVE ADDRESS

\section{REPORT DATE (DD-MM-YYYY) \\ 2. REPORT TYPE \\ 3. DATES COVERED (From - To)}

01-10-2008

Technical Memorandum

\section{TITLE AND SUBTITLE}

Performance of Subscale Docking Seals Under Simulated Temperature Conditions

\section{5a. CONTRACT NUMBER}

5b. GRANT NUMBER

5c. PROGRAM ELEMENT NUMBER

6. AUTHOR(S)

Smith, Ian, M.; Daniels, Christopher, C.; Dunlap, Patrick, H.; Steinetz, Bruce, M.

\section{5d. PROJECT NUMBER}

5e. TASK NUMBER

5f. WORK UNIT NUMBER

WBS 644423.06.31.04.01.03.22

\section{PERFORMING ORGANIZATION}

REPORT NUMBER

E-16605

National Aeronautics and Space Administration

John H. Glenn Research Center at Lewis Field

Cleveland, Ohio 44135-3191

\section{SPONSORING/MONITORING AGENCY NAME(S) AND ADDRESS(ES)}

National Aeronautics and Space Administration

Washington, DC 20546-0001

\section{SPONSORING/MONITORS ACRONYM(S) \\ NASA \\ 11. SPONSORING/MONITORING REPORT NUMBER \\ NASA/TM-2008-215428}

\section{DISTRIBUTION/AVAILABILITY STATEMENT}

Unclassified-Unlimited

Subject Categories: 37 and 18

Available electronically at http://gltrs.grc.nasa.gov

This publication is available from the NASA Center for AeroSpace Information, 301-621-0390

\section{SUPPLEMENTARY NOTES}

\section{ABSTRACT}

A universal docking system is being developed by the National Aeronautics and Space Administration (NASA) to support future space exploration missions to low Earth orbit (LEO), to the moon, and to Mars. The candidate docking seals for the system are a composite design consisting of elastomer seal bulbs molded into the front and rear sides of a metal ring. The test specimens were subscale seals with two different elastomer cross-sections and a 12-in. outside diameter. The seal assemblies were mated in elastomer seal-on-metal plate and elastomer seal-on-elastomer seal configurations. The seals were manufactured from S0383-70 silicone elastomer compound. Nominal and off-nominal joint configurations were examined. Both the compression load required to mate the seals and the leak rate observed were recorded while the assemblies were subjected to representative docking system operating temperatures of $-58,73$, and $122{ }^{\circ} \mathrm{F}(-50,23$, and $50{ }^{\circ} \mathrm{C}$ ). Both the loads required to fully compress the seals and their leak rates were directly proportional to the test temperature.

\section{SUBJECT TERMS}

Low impact docking system; Sealing; Leakage; Load; Force

\begin{tabular}{|c|c|c|c|}
\hline \multicolumn{3}{|c|}{ 16. SECURITY CLASSIFICATION OF: } & \multirow{2}{*}{$\begin{array}{l}\text { 17. LIMITATION OF } \\
\text { ABSTRACT } \\
\text { UU }\end{array}$} \\
\hline $\begin{array}{l}\text { a. REPORT } \\
\text { U }\end{array}$ & $\begin{array}{l}\text { b. ABSTRACT } \\
\mathrm{U}\end{array}$ & $\begin{array}{l}\text { c. THIS } \\
\text { PAGE } \\
\text { U }\end{array}$ & \\
\hline
\end{tabular}

18. NUMBER
OF
PAGES
17

19a. NAME OF RESPONSIBLE PERSON STI Help Desk (email:help@sti.nasa.gov) 19b. TELEPHONE NUMBER (include area code) 301-621-0390 

